\title{
Activation-Induced Cytidine Deaminase
}

National Cancer Institute

\section{Source}

National Cancer Institute. Activation-Induced Cytidine Deaminase. NCI Thesaurus. Code C101415.

Activation-induced cytidine deaminase (198 aa, 24 kDa) is encoded by the human AICDA gene. This protein plays a role in both B-cell functioning and DNA modification. 